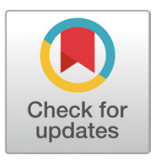

Received: Apr 27, 2020

Revised: Jun 12, 2020

Accepted: Jun 23, 2020

*Corresponding author

Yoon Jung Do

Division of Animal Diseases \& Health

National Institute of Animal Science,

Rural Development Administration,

Wanju 55365, Korea.

Tel: +82-63-238-7222

E-mail: clonea@korea.kr

Copyright $\odot 2020$ Korean Society of Animal Sciences and Technology.

This is an Open Access article distributed under the terms of the

Creative Commons Attribution

Non-Commercial License (http:// creativecommons.org/licenses/by$\mathrm{nc} / 4.0 /$ ) which permits unrestricted non-commercial use, distribution, and reproduction in any medium, provided the original work is properly cited.

ORCID

Seung-Won Yi

https://orcid.org/0000-0001-5545-2969 Ara Cho

https://orcid.org/0000-0001-5309-7721

Eunju Kim

https://orcid.org/0000-0003-4040-0474 Sang-lk Oh

https://orcid.org/0000-0003-0877-9170 Jae Hee Roh

https://orcid.org/0000-0003-4223-1096

Young-Hun Jung

https://orcid.org/0000-0002-8094-0304

Changyong Choe

https://orcid.org/0000-0003-4222-3360

\section{Evaluation of adenosine triphosphate testing for on-farm cleanliness mon- itoring compared to microbiological testing in an empty pig farrowing unit}

\author{
Seung-Won Yi, Ara Cho, Eunju Kim, Sang-lk Oh, Jae Hee Roh, Young-Hun Jung,
} Changyong Choe, Jae Gyu Yoo and Yoon Jung Do*

Division of Animal Diseases \& Health, National Institute of Animal Science, Rural Development Administration, Wanju 55365, Korea

\section{Abstract}

Careful cleaning and disinfection of pigpens is essential to prevent disease spread and avoid the resultant economic losses. Hygiene in pigpens is generally evaluated by visual monitoring supplemented with bacteriological monitoring, which includes counting the total aerobic bacteria (TAB) and/or fecal indicator bacteria (FIB). However, these methods present drawbacks such as time and labor requirements. As adenosine triphosphate (ATP) is ubiquitous in all living organisms including microorganisms, this study aimed to directly compare the results of microbial assessment and ATP quantification, and to suggest possible detailed application methods of the ATP test for hygiene evaluation in pigpens of a farrowing unit. Before and after standard cleaning procedures, samples were collected from the floor corner, floor center, and feeding trough of four pigpens at different time points. No FIB were detected and both the TAB and ATP levels were significantly decreased in the floor center area after cleaning. FIB were continuously detected after cleaning and disinfection of the floor corners, and there was no significant ATP level reduction. The feeding trough did not show any significant difference in these values before and after cleaning, indicating insufficient cleaning of this area. The levels of TAB and ATP after cleaning were significantly correlated and the average ATP value was significantly lower in the absence of FIB than in their presence. In the absence of standard references, a more thorough hygiene management could be achieved evenly by supplementing cleaning or disinfection based on the lowest ATP results obtained at the cleanest test site, which in the present study was the floor center. Overall, these results indicate that the on-farm ATP test can be used to determine the cleanliness status, in addition to visual inspection, as an alternative to laboratory culture-based testing for the presence of microorganisms.

Keywords: Adenosine triphosphate, Hygiene evaluation, Pig farm, Fecal indicator bacteria, Total aerobic bacteria 
Jae Gyu Yoo

https://orcid.org/0000-0002-8542-9193

Yoon Jung Do

https://orcid.org/0000-0003-3207-3514

\section{Competing interests}

No potential conflict of interest relevant to this article was reported.

Funding sources

This study was supported by 2019 RDA

Fellowship Program of the National Institute of Animal Science, Rural Development

Administration, and was carried out with the support of the Cooperative Research Program for Agriculture Science \& Technology Development (Project title: Manual application in response to animal disease crisis and optimization of biosecurity in National Institute of Animal Science, Project No. PJ011915012019), Rural Development Administration, Korea.

Acknowledgements

Not applicable.

Availability of data and material Upon reasonable request, the datasets of this study can be available from the corresponding author.

Authors' contributions

Conceptualization: Yi SW, Kim E, Do YJ.

Data curation: Yi SW, Cho A, Oh SI, Do YJ.

Formal analysis: Cho A, Oh SI.

Methodology: Yi SW, Kim E.

Validation: Cho A, Oh SI, Do YJ.

Investigation: Roh JH, Jung YH, Choe C, Yoo JG.

Writing - original draft: Yi SW, Cho A, Do YJ

Writing - review \& editing: Kim E, Oh SI, Roh JH, Jung YH, Choe C, Yoo JG.

Ethics approval and consent to participate This article does not require IRB/IACUC approval because there are no human and animal participants.

\section{INTRODUCTION}

Livestock biosecurity reduces the likelihood of pathogen entry and spread in livestock barns through processes such as cleaning and disinfection. A previous study reported that the implementation and effective monitoring of biosecurity can prevent losses due to African swine fever with a profit:cost ratio of 29 [1]. In addition to blocking the entry of external pathogens into the pig barn, careful cleaning and disinfection management are required as internal biosecurity measures to prevent the spread of endemic disease pathogens such as the porcine respiratory disease complex or diseases of the digestive system that cause substantial economic losses. A previous study reported that annual production losses due to the porcine reproductive and respiratory syndrome in the American swine industry were estimated to be approximately $\$ 664$ million [2]. Internal biosecurity involves cleaning and disinfection, which are essential processes for hygiene management in contemporary animal facilities $[3,4]$. However, in contrast to the highly standardized processes used in external biosecurity, pig-raising facilities do not currently have a high standard for internal biosecurity [5]. In a typical pigpen, the floor is the major living space for pigs and can be easily contaminated with various living and non-living organic materials such as body fluids and feces. These residual organic materials can support microbial growth, including that of opportunistic pathogenic bacteria [6]. In particular, as farrowing units are in direct contact with residual feces, the pigpen environment could be contaminated, increasing chances of infection by opportunistic pathogens in pigs or piglets through licking their bodies or sucking sows. Moreover, the feed and facilities used for feeding and drinking can become contaminated. Indeed, previous studies have shown high levels of contamination in feeding troughs [7,8], which are critical sites after disinfection [4]. Although the importance of cleaning and disinfection has been emphasized to pig farmers, these recommendations are largely based on practical experience rather than scientifically established data [9].

Hygiene evaluations are commonly conducted by visual inspection; however, previous studies have demonstrated that visual inspection alone is a poor indicator of cleaning efficacy [10,11]. After cleaning and disinfection, bacteriological monitoring can be performed by counting total aerobic bacteria (TAB) and/or fecal indicator bacteria (FIB) $[4,12,13]$. To date, the assessment of contamination levels and disinfection effects in pig farm management have mainly been conducted using laboratory bacterial tests. The commonly used TAB count, as a classical culture-based analysis, can take up to $72 \mathrm{~h}$ to provide results and is labor-intensive. To overcome these drawbacks, the adenosine triphosphate (ATP) bioluminescence measurement method was recently introduced, and has been increasingly adopted to monitor appropriate cleaning [12-17]. As ATP is present in all living organisms including microorganisms, its presence and levels serve as useful indicators of contamination with organic materials that support microbial growth [6]. Enumeration of microbial contamination and the ATP test are standardized methods for hygiene evaluation in food production facilities, hospitals, and drug companies $[6,15,18]$. In addition, these methods are commonly employed in the livestock industry for examining the hygiene status of slaughterhouses, transporting trailers, and meat-processing facilities [4,19-23]. The ATP test for on-farm inspection was recently suggested as a substitute for laboratory testing based on a study comparing various inspection methods [24]. However, the study focused on the improvements in hygiene status after educating farmers on how to perform the ATP test along with other methods and how to use them after cleaning; the detailed application of the ATP test in the absence of reference values to indicate cleanliness status at livestock farms was not presented.

Therefore, with the goal of strengthening internal biosecurity management in an empty pig farrowing unit, the aim of the present study was to directly compare the results of classical microbial assessment methods and the ATP test as on-farm monitoring methods. In addition, we suggest 
detailed applications of the ATP test to determine cleanliness status along with visual inspection as an alternative to laboratory culture-based testing for the presence of microorganisms.

\section{MATERIALS AND METHODS}

\section{Sampling}

This study was carried out in a farrowing unit of the experimental pig house of the National Institute of Animal Science (wanju, Korea). The farrowing unit consisted of eight pens of $1.8 \times 2.4 \mathrm{~m}^{2}$ each with a polypropylene grid floor. Sows and piglets were removed from the pens after residing there for 4 weeks during the weaning period. After the pigs were removed, each pen was cleaned manually with a high-pressure water spray gun. After visually ensuring the removal of organic matter, a potassium peroxymonosulfate-based disinfectant (Virkon S, Lanxess, Cologne, Germany) diluted at 1:200 with water was dispensed into the atmosphere and floor from the top of each pig pen using a mass automatic spraying disinfection system. Samples were collected from the surfaces of the following sites: floor centers, floor corners, and feeding troughs of four pens (Fig. 1). Tests under the same conditions were performed by swab sampling before cleaning, after cleaning, and at $1 \mathrm{~h}, 3 \mathrm{~h}$, $6 \mathrm{~h}, 24 \mathrm{~h}, 48 \mathrm{~h}, 5$ days, and 7 days after disinfection.

\section{Determination of ATP bioluminescence}

The ATP level of each sampled area was determined based on the measurement of ATP bioluminescence intensity with a luminometer (Lumitester PD-30, Kikkoman, Tokyo, Japan) according to the manufacturer's instructions. Dry swabs (LuciPac Pen swabs, Kikkoman) were pre-moistened with sterilized and $0.45 \mu \mathrm{m}$-filtered distilled water. The swabs were used to collect samples from each $625 \mathrm{~cm}^{2}$ area. The swabs were inserted into a LuciPac Pen tube containing lyophilized luciferin and luciferase powder, which was then shaken for mixing reagent and sample.

\section{Determination of microbial loads}

Cotton swabs were pre-moistened with sterilized $0.85 \%$ saline solution and used to sample the surfaces of the three different target sites of the pig farrowing unit. Following sampling, the swabs were placed in $9 \mathrm{~mL}$ of $0.85 \%$ saline and soaked for $1 \mathrm{~h}$. One milliliter of these swab mixtures was

(c) (a) (b)

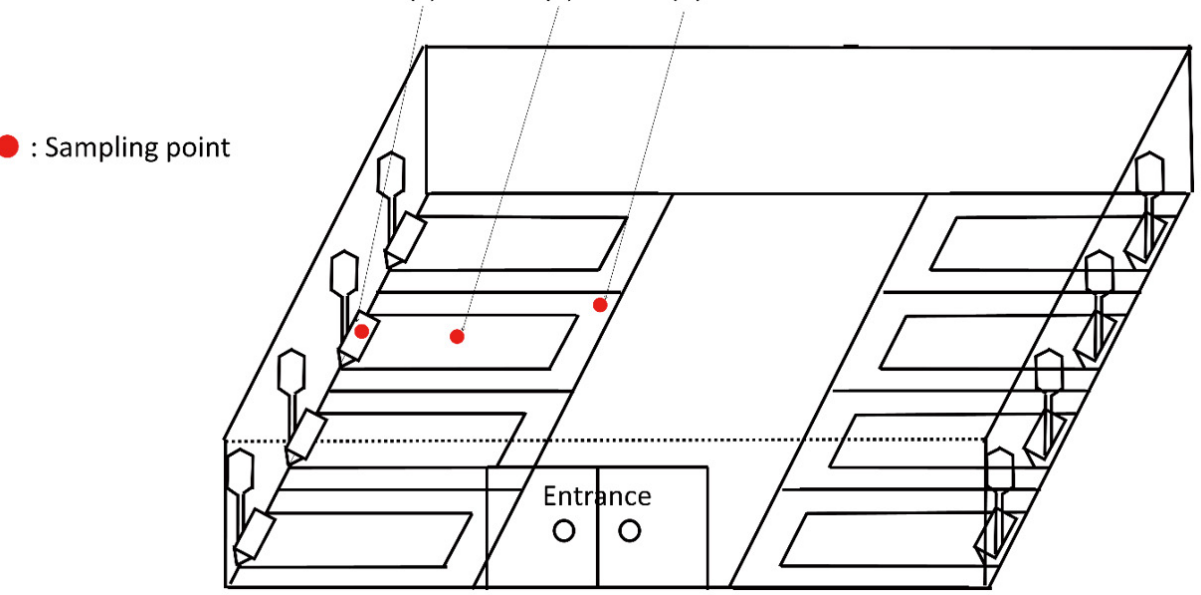

Fig. 1. Sampling sites for comparison of the adenosine triphosphate (ATP) test and microbial status based on colony counts at an empty pig farrowing unit. (a) Floor center, (b) floor corner, (c) feeding trough. 
serially diluted in 10-fold increments. The original suspensions and each dilution were inoculated on three types of dry rehydratable film plates (3M Petrifilm AC Plate, CC Plate, and EC Plate; all from 3M, Minneapolis, MN, USA) for the enumeration of TAB, and coliforms and Escherichia coli as FIB. After incubating the $\mathrm{CC}$ and $\mathrm{EC}$ plates at $37^{\circ} \mathrm{C}$ for $18-24 \mathrm{~h}$, the red colonies with gas bubbles on CC plates, and the blue colonies with gas bubbles on EC plates, were counted as coliforms and E. coli, respectively. In addition, following incubation of the $\mathrm{AC}$ plates at $37^{\circ} \mathrm{C}$ for up to $48 \mathrm{~h}$, the red colonies were counted as TAB. Bacterial counts were converted into log colony-forming units (CFU)/625 $\mathrm{cm}^{2}$ for analysis.

\section{Statistical analysis}

Our data were arranged in spreadsheets using Excel 2010 software (Microsoft, Redmond, WA, USA) and statistically analyzed using SPSS software (version 22.0, IBM, Armonk, NY, USA). The paired Student's $t$-test was used to assess the significance of differences between the conditions before and after cleaning and disinfection. The correlation between ATP levels and TAB counts was analyzed using Spearman's rank correlation coefficient ( $r$ ) from data after cleaning. In addition, significant differences in ATP values according to the presence or absence of FIB after cleaning were assessed using Student's $t$-test. A $p$-value $<0.05$ was considered statistically significant.

\section{RESULTS}

\section{ATP and microbiological testing according to sampling sites \\ Floor center}

Compared to the mean ATP bioluminescence levels measured before cleaning, significantly lower levels $(p=0.017)$ were observed after cleaning the floor center, and persisted up to $48 \mathrm{~h}$ after disinfection (Fig. 2A). However, $6 \mathrm{~h}$ after disinfection, these levels began to increase, and after $48 \mathrm{~h}$, they exceeded the levels measured immediately after cleaning. There was no difference in the level measured 5 days after disinfection. The TAB count also decreased significantly until $6 \mathrm{~h}$ after disinfection, with a reduction of $2.61 \mathrm{Log} \mathrm{CFU} / 625 \mathrm{~cm}^{2}$ compared to that measured before cleaning. However, $24 \mathrm{~h}$ after disinfection, TAB counts began to steadily increase and showed no significant difference compared to those before cleaning. FIB, including coliforms and E. coli, were not detected on the floor center after cleaning and from $3 \mathrm{~h}$ after disinfection until the end of the experiment.

\section{Floor corner}

The mean ATP bioluminescence level of the floor corner measured after cleaning was not signifcantly different from that measured before cleaning (Fig. 2B). This level was at its lowest immediately after cleaning but increased $1 \mathrm{~h}$ after disinfection and remained at the level measured before cleaning until the end of the experiment. Conversely, the mean TAB count decreased significantly $(p=0.021)$ immediately after cleaning with a reduction of $0.78 \mathrm{Log} \mathrm{CFU} / 625 \mathrm{~cm}^{2}$ compared to that measured before cleaning. From $1 \mathrm{~h}$ to $24 \mathrm{~h}$ after disinfection, the TAB counts increased, showing no significant difference compared with those measured before cleaning, and then began to decrease significantly $48 \mathrm{~h}$ after disinfection, with a reduction of $0.84-1.21 \log \mathrm{CFU} / 625 \mathrm{~cm}^{2}$. Significantly less FIB were observed after cleaning compared to those enumerated before cleaning, with a reduction of $0.45 \mathrm{Log} \mathrm{CFU} / 625 \mathrm{~cm}^{2}(p=0.008)$, although high standard deviations were observed among the bacterial enumerations. However, there was no difference between the values obtained between $1 \mathrm{~h}$ and $24 \mathrm{~h}$ after disinfection. The FIB counts began to decrease significantly 48 $\mathrm{h}$ after disinfection. No colony growth was detected 5 days after disinfection, but this count began to increase again 7 days after disinfection. 

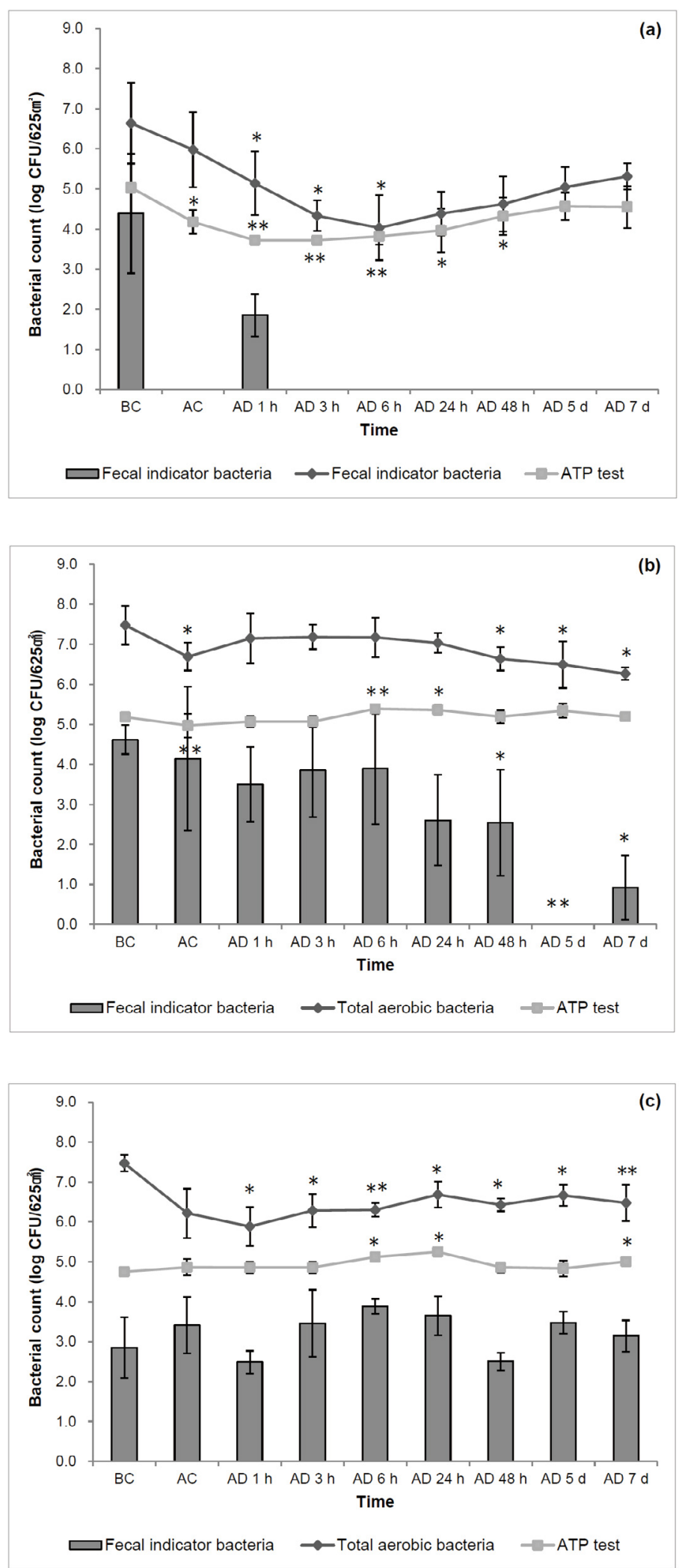

Fig. 2. Comparison of adenosine triphosphate (ATP) test and microbial status results from plate counting (total aerobic bacteria, fecal indicator bacteria) according to the cleaning status of the (a) floor center, (b) floor corner, and (c) feeding trough of the pig farrowing unit ( $p<0.05, " p<0.01$ vs BC). BC, before cleaning; $A C$, after cleaning; $A D$, after disinfection. 


\section{Feeding trough}

Despite cleaning and disinfection, there were no significant decreases in mean ATP bioluminescence levels or FIB counts in the feeding trough (Fig. 2C). Moreover, the ATP bioluminescence level increased significantly $6 \mathrm{~h}, 24 \mathrm{~h}$, and 7 days after disinfection. A lower mean TAB count was observed after cleaning compared to that measured before cleaning. Although the counts began increasing again from $3 \mathrm{~h}$ to 7 days after disinfection, they were still significantly lower than those measured before cleaning.

\section{Correlations between TAB and ATP levels}

The TAB results were significantly correlated with those of overall ATP levels after cleaning; however, this correlation depended on the sampling sites, with a significant correlation found for the floor center and feeding trough but not for the floor corner of the pig farrowing unit (Fig. 3). Therefore, the analyses performed to determine whether the presence of FIB affects the correlation inside the pig barn showed a significant correlation in the absence of FIB $(r=0.621, p<0.001)$, but only a relatively weak correlation in the presence of FIB $(r=0.371, p=0.037)$.

ATP levels according to the presence or absence of fecal indicators

After cleaning, there was no correlation between ATP values and the presence of FIB. However, the average ATP value was significantly lower in the absence of FIB than in their presence $(p<0.001$; Fig. 4).

\section{DISCUSSION}

\section{Comparison of microbial status and ATP test results according to the cleanliness}

\section{of sampling sites}

Our results showed that organic materials were appropriately removed by cleaning and disinfection of the floor center area, as no FIB were detected and both the TAB and ATP levels were significantly decreased. Although this effect was maintained throughout the study period, a small amount

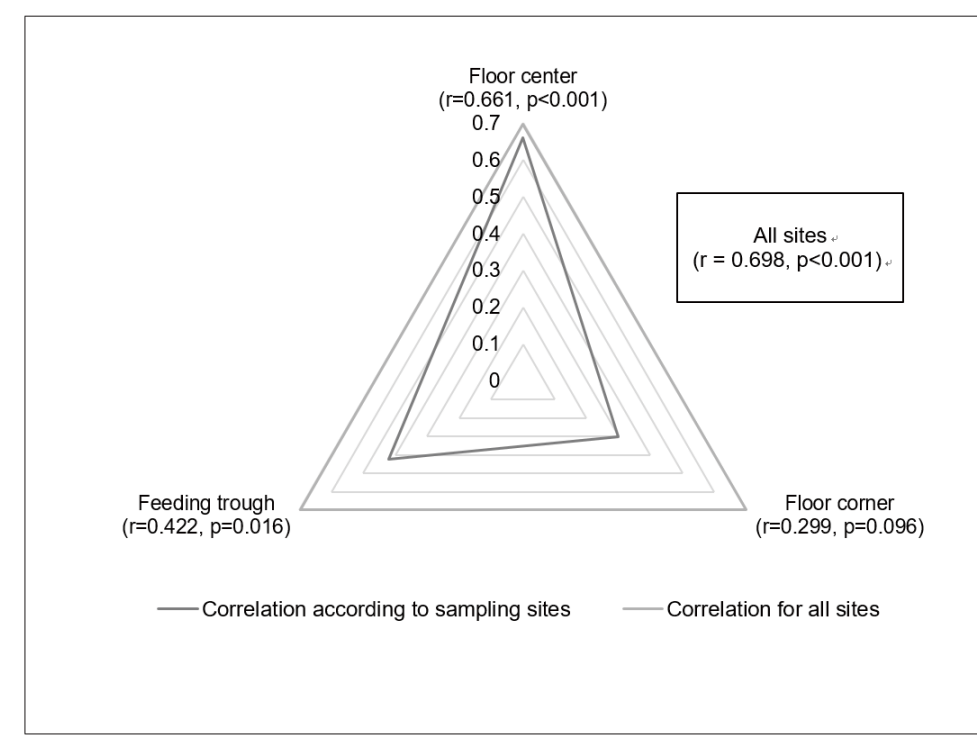

Fig. 3. Correlation coefficients between total aerobic bacteria (TAB) and adenosine triphosphate (ATP) levels according to the sampling sites inside the pig farrowing unit. 


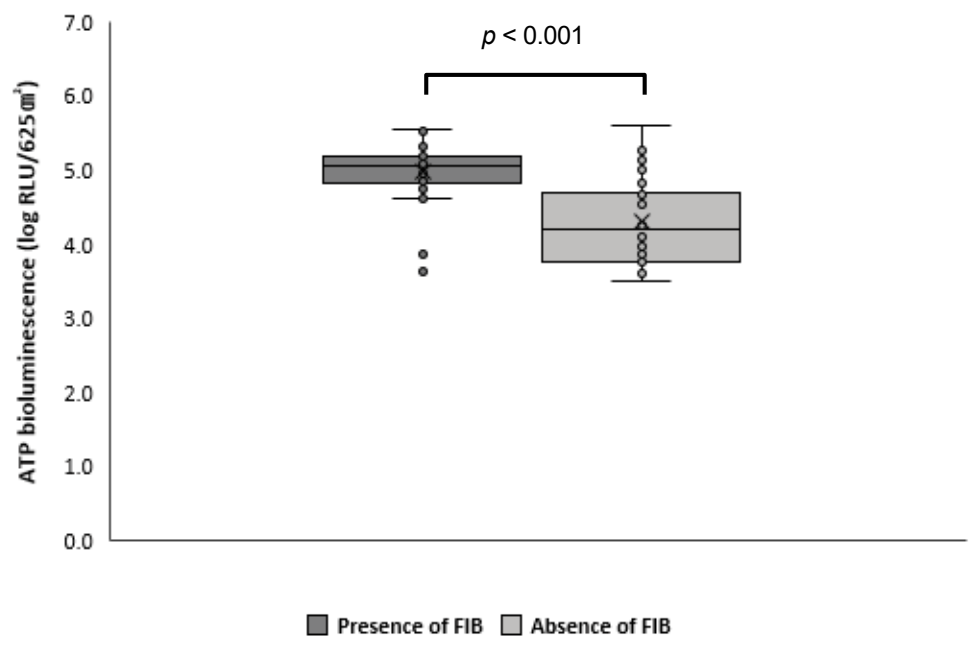

Fig. 4. Means, distributions, and standard deviations of adenosine triphosphate (ATP) values according to the presence or absence of fecal indicator bacteria (FIB).

of FIB was temporarily detected $1 \mathrm{~h}$ after disinfection.

Fecal organic materials were considered to be insufficiently removed in the floor corner and feeding trough areas as FIB were continuously detected after cleaning and disinfection, and there was no significant reduction in ATP levels in these areas. Although the TAB level decreased immediately after cleaning in the floor corner and after disinfection in the feeding trough, the effects in the latter could not be confirmed. The efficacy of disinfection highly depends on the precision of initial cleaning, as the remaining organic material can significantly reduce the effect of disinfection [24-26]. Therefore, the subsequent effect of disinfection considering inadequate cleaning is believed to have a delayed or reduced bactericidal effect in this study. Feeders and drinkers (including nipple drinkers) are considered the most critical aspects of cleaning and disinfection procedures and can become more contaminated than floors after sanitation due to resoiling during power washing from the splashing of contaminated water $[8,24]$. We were unable to determine the possibility of recontamination during high-pressure spraying; however, the removal of fecal organic matter from the floor corners and feeding trough did not seem sufficient, whereas the floor center was appropriately cleaned. Pathogens from pigs previously reared in these areas can be easily transferred to newly arriving pigs through feeders and drinkers. In particular, proper cleaning and disinfection before stocking new pregnant pigs in a farrowing unit are very important to prevent the spread of infectious agents to piglets with poor disease defenses. In contrast to our findings, a previous study suggested that floors were also a critical area of concern in cleaning and disinfecting pig barns when compared with walls [27]. However, a more recent study showed that the feeder and drinker components were more heavily contaminated, which is in line with our results, and that the floor and manure areas had relatively low levels of contamination after cleaning and disinfection [24].

Therefore, our study confirmed that the cleaning at the corners of the pigpen was not sufficient and that subsequent disinfection did not compensate for this lapse. Based on previous findings and the present results, thorough cleaning and disinfection from the floor center to the corner should be performed in addition to detailed cleaning of the pigs' internal facilities. To this end, it is necessary to consider how farmers can evaluate objective contamination levels in addition to visual inspection at farm sites. 
Possible applications of the ATP test to maintain cleanliness throughout empty pig barns

Previous studies have also examined the value of the ATP test as an objective and rapid method for measuring contamination levels in livestock farms and related industrial sites [4,19-24]. Although there is no report on a standard for contamination that can be interpreted objectively and no specific application method is provided at farm sites, Heinemann et al. [24] recently reported that training farmers on how to apply the ATP test resulted in an improvement of internal sanitation at a pig barn. To enhance internal sanitation management using the ATP test in pig farrowing units, it is necessary to suggest more specific ways to apply this method. Therefore, we compared the test results of TAB counts and ATP levels by examining the areas where the most organic material was removed and areas where organic material remained after cleaning and disinfection, demonstrating an overall significant correlation between the two methods for the pig farrowing unit.

The levels of TAB and ATP showed a high significant correlation $(r=0.698, p<0.001)$ after cleaning, which is in line with the results of the previous study $(r=0.82, p<0.001)$ [24]. However, the correlation was weaker when fecal bacteria were detected than in their absence. This difference suggests that the reliability of the result should be improved when sufficient cleaning and careful visual inspection are performed before the ATP test in a pig barn. In addition, the result of the ATP test was significantly lower when FIB were considered thoroughly removed, as in the floor center where no FIB were detected, when compared to areas with remaining FIB (floor corner and feeding trough). This result indicates that a cleaner state inside a pig barn can be distinguished by the ATP test. Therefore, after visually checking the overall cleanliness, more thorough hygienic management can be achieved evenly by supplementing the cleaning or disinfection based on the lowest ATP test results. Therefore, when using the ATP test in a pig barn, it is necessary to compare the results to the value obtained at the cleanest site after careful cleaning.

To make the ATP test results more precise and easier to understand, so that they can be used by pig farms, it is necessary to establish a reference range for the ATP test results that can be recognized as clean, which requires further research. In addition, since the ATP test does not identify specific pathogens, guidance should be provided considering cleanliness and disinfection according to the specific disease occurrence characteristics of the farm, regardless of the ATP test results.

Heinemann et al. [24] showed a higher correlation between TAB count and ATP levels compared to those obtained in the present study, although the previous study did not compare the status of organic matter removal at each sampling site. In our study, the correlation between TAB count and ATP levels was significantly high when FIB were sufficiently removed, and this numerical value was significantly decreased in the well-cleaned area. This finding suggests that the ATP test would be an effective method for managing the hygiene status of the remaining facilities, equipment, and floor corners based on results from the floor center, which is more easily cleaned. Although the present experiment was conducted on several pens in a pig farrowing unit for repeated tests under the same conditions, these results may also be applicable to other pig rooms. Notably, the cleanest site will differ depending on the farm environment; thus, it is necessary to select the cleanest site according to each farm's standard through repeated inspection by the farmer. It is also expected that these repetitive tests can contribute to establish an ATP standard level for the cleanest state according to the farmers' satisfaction.

\section{REFERENCES}

1. Fasina FO, Lazarus DD, Spencer BT, Makinde AA, Bastos ADS. Cost implications of African swine fever in smallholder farrow-to-finish units: economic benefits of disease prevention 
through biosecurity. Transbound Emerg Dis. 2012;59:244-55. https://doi.org/10.1111/j.18651682.2011.01261.x

2. Holtkamp DJ, Kliebenstein JB, Neumann E, Zimmerman JJ, Rotto H, Yoder TK, et al. Assessment of the economic impact of porcine reproductive and respiratory syndrome virus on United States pork producers. J Swine Health Prod. 2013;21:72-84.

3. Madec F. The role of animal hygiene and health management in pig production. In: Proceedings of the XIIth International Congress, International Society for Animal Hygiene (ISAH) 2005, 2005. Warsaw, Poland. p. 40-8.

4. Luyckx K, Millet S, Van Weyenberg S, Herman L, Heyndrickx M, Dewulf J, et al. A 10-day vacancy period after cleaning and disinfection has no effect on the bacterial load in pig nursery units. BMC Vet Res. 2016;12:236. https://doi.org/10.1186/s12917-016-0850-1

5. Gleeson BL, Collins AM. Under what conditions is it possible to produce pigs without using antimicrobials? Anim Prod Sci. 2015;55:1424-31. https://doi.org/10.1071/an15271

6. Willis C, Morley R, Westbury J, Greenwood M, Pallett A. Evaluation of ATP bioluminescence swabbing as a monitoring and training tool for effective hospital cleaning. Br J Infect Control. 2007;8:17-21. https://doi.org/10.1177/1469044607083604

7. Rufete B, Perez-Murcia MD, Perez-Espinosa A, Moral R, Moreno-Caselles J, Paredes C.Total and faecal coliform bacteria persistence in a pig slurry amended soil. Livest Sci. 2006;102:2115. https://doi.org/10.1016/j.livsci.2006.03.019

8. Mannion C, Leonard FC, Lynch PB, Egan J. Efficacy of cleaning and disinfection on pig farms in Ireland. Vet Rec. 2007;161:371-5. https://doi.org/10.1136/vr.161.11.371

9. Corrégé I, Dubroca S. Efficacy and cost comparison of different cleaning and disinfecting processes for pig farms. In: Proceedings of the International Society for Animal Hygiène, 2004 Oct 11-13; Saint-Malo.

10. Hancox LR, Le Bon M, Dodd CER, Mellits KH. Inclusion of detergent in a cleaning regime and effect on microbial load in livestock housing. Vet Rec. 2013;173:167. https://doi. org/10.1136/vr.101392

11. Mustafa EA, Babeker HAA. Evaluation of the efficacy of cleaning and disinfection in broiler farms between rest periods in Khartoum state, Sudan. World J Pharm Pharm Sci. 2018;7:10919. https://doi.org.10.20959/wjpps20187-11893

12. Colquhoun KO, Timms S, Fricker CR. A simple method for the comparison of commercially available ATP hygiene-monitoring systems. J Food Prot. 1998;61:499-501. https://doi. org/10.4315/0362-028x-61.4.499

13. Davidson CA, Griffith CJ, Peters AC, Fielding LM. Evaluation of two methods for monitoring surface cleanliness: ATP bioluminescence and traditional hygiene swabbing. Luminescence. 1999;14:33-8. https://doi.org/10.1002/(sici)1522-7243(199901/02)14:1<33::aidbio514>3.0.co;2-i

14. Peters A, Mortlock M, Griffith C, Lloyd D. Evaluating impact of food safety control on retailer butchers. In: Hooker NH, Murano EA, editors. Interdisciplinary food safety research. Boca Raton, Fl: CRC Press; 2001.p.175-98.

15. Aycicek H, Oguz U, Karci K. Comparison of results of ATP bioluminescence and traditional hygiene swabbing methods for the determination of surface cleanliness at a hospital kitchen. Int J Hyg Environ Health. 2006;209:203-6. https://doi.org/10.1016/j.ijheh.2005.09.007

16. Hwang CC, Kung HF, Lin CS, Hwang DF, Tsai YH. Bacteriological quality and histamine-forming bacteria associated with fish meats and environments in HACCP and non-HACCP fish processing factories. Food Control. 2011;22:1657-62. https://doi. org/10.1016/j.foodcont.2011.03.025 
17. Luyckx K, Dewulf J, Van Weyenberg S, Herman L, Zoons J, Vervaet E, et al. Comparison of sampling procedures and microbiological and non-microbiological parameters to evaluate cleaning and disinfection in broiler houses. Poult Sci. 2015;94:740-9. https://doi.org/10.3382/ ps/pev019

18. Lee JH. An investigation of factors that influence hygiene practices at a small day care center.J Food Prot. 2018;81:158-64. https://doi.org/10.4315/0362-028X.JFP-17-163

19. Amass SF, Thompson B, Dimmich KM, Gaul AM, Schneider JL. Impact of downtime on reducing aerobic bacterial counts in cleaned and disinfected trailers. J Swine Health Prod. 2007;15:37-41.

20. Sala C, Milovan GH, Morar A, Nichita I. Establishing the microbial contamination of surfaces from the food industry by alternative methods using ATP bioluminescence. Lucrăr Stiinfifice Medicină Veterinară. 2008;41:841-6.

21. Oshita S, Al-Haq MI, Kawagishi S, Makino Y, Kawagoe Y, Ye X, et al. Monitoring of ATP and viable cells on meat surface by UV-Vis reflectance spectrum analysis. J Food Eng. 2011;107:262-7. https://doi.org/10.1016/j.jfoodeng.2011.06.007

22. Oto N, Oshita S, Makino Y, Kawagoe Y, Sugiyama J, Yoshimura M. Non-destructive evaluation of ATP content and plate count on pork meat surface by fluorescence spectroscopy. Meat Sci. 2013;93:579-85. https://doi.org/10.1016/j.meatsci.2012.11.010

23. Cabahug JP, Alvarado AC, Predicala BZ. Rapid assessment of cleanliness of commercial hog transport trailers using ATP bioluminescence method. In: Proceedings of the ASABE 2016: Annual International Meeting; 2016. Orlando, Fl.

24. Heinemann C, Meyer I, Bögel FT, Schmid SM, Hayer JJ, Steinhoff-Wagner J. Individual training for farmers based on results from protein and ATP rapid tests and microbiological conventional cultural methods improves hygiene in pig fattening pens. J Anim Sci. 2020;98:skz389. https://doi.org/10.1093/jas/skz389

25. Ward PJ, Fesenko GM, Gibson S, McMullen LM. A microbiological assessment of on-farm food safety cleaning methods in broiler barns. J Appl Poult Res. 2006;15:326-32. https://doi. org/10.1093/japr/15.2.326

26. Gosling RJ. A review of cleaning and disinfection studies in farming environments. Livestock. 2018;23:232-7. https://doi.org/10.12968/live.2018.23.5.232.

27. Vangroenweghe F, Heylen P, Arjs D, Castryck F. Hygienograms for evaluation of cleaning and disinfection protocols in pig facilities. In: Proceedings of the Eighth International Symposium on the Epidemiology and Control of Foodborne Pathogens in Pork; 2009. Quebec, QU. 